\title{
Comparing Evapotranspiration Estimates from the GEOframe-Prospero Model with Penman-Monteith and Priestley-Taylor Approaches under Different Climate Conditions
}

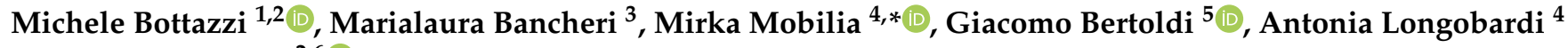 \\ and Riccardo Rigon 2,6 (D) \\ 1 CINECA Consorzio Interuniversitario, 40033 Bologna, Italy; m.bottazzi@cineca.it \\ 2 Department of Civil, Environmental and Mechanical Engineering, University of Trento, 38123 Trento, Italy; \\ riccardo.rigon@unitn.it \\ 3 Institute for Mediterranean Agricultural and Forestry Systems (ISAFOM), National Research Council (CNR), \\ 80055 Portici, Italy; marialaura.bancheri@isafom.cnr.it \\ 4 Department of Civil Engineering, University of Salerno, 84084 Fisciano, Italy; alongobardi@unisa.it \\ 5 Institute for Alpine Environment, Eurac Research, 39100 Bolzano, Italy; giacomo.bertoldi@eurac.edu \\ 6 C3A-Center Agriculture Food Environment, University of Trento, 38010 San Michele all'Adige, Italy \\ * Correspondence: mmobilia@unisa.it
}

check for updates

Citation: Bottazzi, M.; Bancheri, M.; Mobilia, M.; Bertoldi, G.; Longobardi, A.; Rigon, R. Comparing Evapotranspiration Estimates from the GEOframe-Prospero Model with Penman-Monteith and Priestley-Taylor Approaches under Different Climate Conditions. Water 2021, 13, 1221. https://doi.org/ 10.3390/w13091221

Academic Editor: Gianfranco Rana

Received: 31 March 2021

Accepted: 26 April 2021

Published: 28 April 2021

Publisher's Note: MDPI stays neutral with regard to jurisdictional claims in published maps and institutional affiliations.

Copyright: (C) 2021 by the authors. Licensee MDPI, Basel, Switzerland. This article is an open access article distributed under the terms and conditions of the Creative Commons Attribution (CC BY) license (https:// creativecommons.org/licenses/by/ $4.0 /)$.

\begin{abstract}
Evapotranspiration (ET) is a key variable in the hydrological cycle and it directly impacts the surface balance and its accurate assessment is essential for a correct water management. ET is difficult to measure, since the existing methods for its direct estimate, such as the weighing lysimeter or the eddy-covariance system, are often expensive and require well-trained research personnel. To overcome this limit, different authors developed experimental models for indirect estimation of ET. However, since the accuracy of ET prediction is crucial from different points of view, the continuous search for more and more precise modeling approaches is encouraged. In light of this, the aim of the present work is to test the efficiency in predicting ET fluxes in a newly introduced physical-based model, named Prospero, which is based on the ability to compute the ET using a multi-layer canopy model, solving the energy balance both for the sunlight and shadow vegetation, extending the recently developed Schymanski and Or method to canopy level. Additionally, Prospero is able to compute the actual ET using a Jarvis-like model. The model is integrated as a component in the hydrological modelling system GEOframe. Its estimates were validated against observed data from five Eddy covariance (EC) sites with different climatic conditions and the same vegetation cover. Then, its performances were compared with those of two already consolidated models, the Priestley-Taylor model and Penman FAO model, using four goodness-of-fit indices. Subsequently a calibration of the three methods has been carried out using LUCA calibration within GEOframe, with the purpose of prediction errors. The results showed that Prospero is more accurate and precise with respect to the other two models, even if no calibrations were performed, with better performances in dry climatic conditions. In addition, Prospero model turned to be the least affected by the calibration procedure and, therefore, it can be effectively also used in a context of data scarcity.
\end{abstract}

Keywords: evapotranspiration; GEOframe-Prospero model; Priestley-Taylor model; Penman-FAO model; calibration

\section{Introduction}

The estimation of atmospheric turbulent fluxes (sensible and latent heat) at the land surface has long been recognized as the most important issue in the determination of the exchanges of energy and mass among hydrosphere, atmosphere and biosphere (e.g., [1-8]) and thus, it is of critical importance to the hydrological and energy cycles [9,10]. At global scale, the overland latent heat represents the $38 \%$ of the net radiation absorbed and the corresponding evapotraspiration (ET) amounts to $40 \%$ of total precipitation. Transpiration (T) 
impacts on the ET up to $60 \%$. However, ET, and, in particular, its separation in E and T [11], is still difficult to directly measure, and, as reported in [12], current land surface models provide different ratios of the T by vegetation to total ET. Moreover, for some ecosystems, such as the forested mountains of the European Alps, there is a large uncertainty associated with the vegetation response to water stress [13].

Plant water-use strategies are driven by plant functional traits (examples are leaf size, toughness and longevity, seed size and dispersal mode, canopy height and structure, capacity for nitrogen fixation, stomatal response to environmental forcing [14]). In recent years, plant physiology studies provided an increasingly detailed knowledge of plant behaviour [15], but only some of them were implemented in eco-hydrological models [16], mostly confined to specific studies [17-19]. Vegetation hydraulic was recently reviewed by Stroock et al. [20], providing the idea that a new synthesis is necessary between the modelling of water and carbon fluxes, providing further evidence that an upscaling from cells through plants to landscape is required.

In recent years, the development of worldwide networks such as the Long-Term SocioEcological Research (LTSER) or FLUXNET has led to a deeper experimental knowledge of plant-water interactions. At the same time, new and improved techniques for area-wide observations (proximal sensing through Unmanned Aerial Vehicle (UAV) devices, Remote Sensing (RS) platforms as European Space Agency (ESA) satellite Sentinel mission [21]) have provided new options for upscaling models to landscape-scale.

Despite the large number of existing ET empirical models [22], the increasing experimental knowledge of plant's hydrology and the availability of high-resolution observations, there is still a lack of appropriate modelling methods able to incorporate this information in a physically consistent way [23], while gathering and blending information from atmospheric boundary layer meteorology, hydrology, plant physiology, thermodynamics and fluid dynamics. In fact, there is a need to build reliable, robust and realistic predicting modelling tools, to translate this observational knowledge in mathematical and numerical form, combining functional complexity with practical needs [24].

Modellers had to face different challenges, such as joining the plant physiology with the biosphere and considering the interactions with water, soil and atmosphere (including spatial and temporal patterns). These tasks involve: (i) an appropriate modelling of the environmental conditions $[25,26]$; (ii) the mathematical description of the water flow in the soil and subsoil, considering the interaction roots and the reciprocal influence of plants for accessing nutrient resources [27]; (iii) a more accurate separation of soil E (E) from $\mathrm{T}$ [28]; (iv) the need to upscale the mathematics of plants behaviour at the landscape scale, with the appropriate degree of complexity [29]; (v) development of user-friendly tools [30] for applied purposes that can easily be integrated in large modelling frameworks [31].

In an attempt to address the previous points, the scope of this work is to present a new model, the GEOframe-Prospero, which considers both the E from the soil and T from the canopy, both shaded and at sunlit. The E from soil is computed with a PenmanMonteith (called PM) FAO process [32], with specific coefficients for soil E depending on the case study. $\mathrm{T}$ is computed starting from the Schymanski and Or method [33] (SO). In fact, this approach has the advantage of an explicit solution to the surface energy budget as the classical PM model, but it has ensured the best estimation of latent heat from a leaf. However, the SO equation has been upscaled in order to face the canopy $\mathrm{T}$ and the mass conservation. The model is implemented as a component in the GEOframe modelling system [34,35], which allows for the simulation of all the hydrological variables of the water budget at catchment scale. The integration of Prospero model within the GEOframe environment allows for the flexibility required to deal with multiple scale processes, and to switch different componentsoff or on, depending on the specific user's needs. The component-based modelling system, built on top of the Object Modelling System [31] allows for multiple modelling solutions for the same physical process, such as, for instance, ET. 
The Prospero (PS) model has been tested in five different Eddy-covariance sites across the world, belonging to the FLUXNET network. The sites are: (i) AU-Dry in Northern Territory of Australia located at an elevation of $180 \mathrm{~m}$ a.s.1.; (ii) US-Cop in Utah, United States with an altitude of $1520 \mathrm{~m}$; (iii) US-Var in California, United States at $129 \mathrm{~m}$ a.s.l; (iv) IT-Tor in Aosta Valley, Italy at the altitude of $2160 \mathrm{~m}$ a.s.l.; (v) GL-ZaH in Sermersooq, Greenland at $38 \mathrm{~m}$. a.s.l. They differ in terms of climatic regime but not in terms of land cover. Indeed, the sites are located in tropical, arid, temperate, continental and polar climates which are the five main climate groups, and the dominant vegetation type is grassland. In detail, the grassland cover mainly consists of herbaceous and other understory systems in AU-Dry, perennial grasses in US-Cop, grasses and herbs in US-Var, herbaceous types in IT-Tor and patches of mosses in GL-ZaH. The grassland cover has been selected as it is one of the largest biomes on earth [36]. The accuracy of PS in predicting ET has been compared to those of the Priestley-Taylor and Penman FAO models, which are two of the most widely used methods in the scientific literature [37] in case of both calibrated and non-calibrated approaches.

\section{Methodology}

\subsection{Case Studies}

Five Eddy-covariance experimental sites have been selected as case studies. They belong to the global FLUXNET network (https: / fluxnet.org/, accessed on 27 April 2021), which provides observational data of eddy covariance fluxes at different flux tower sites around the world. The chosen sites are:

- $\quad$ AU-Dry (10.18140/FLX/1440197) in Northern Territory of Australia;

- $\quad$ US-Cop (10.18140/FLX/1440100) in Utah, United States;

- US-Var (10.18140/FLX/1440094) in California, United States;

- $\quad$ IT-Tor (10.18140/FLX/1440237) in Aosta Valley, Italy;

- GL-ZaH (10.18140/FLX/1440224) in Sermersooq, Greenland.

The location of each site is shown in Figure 1.

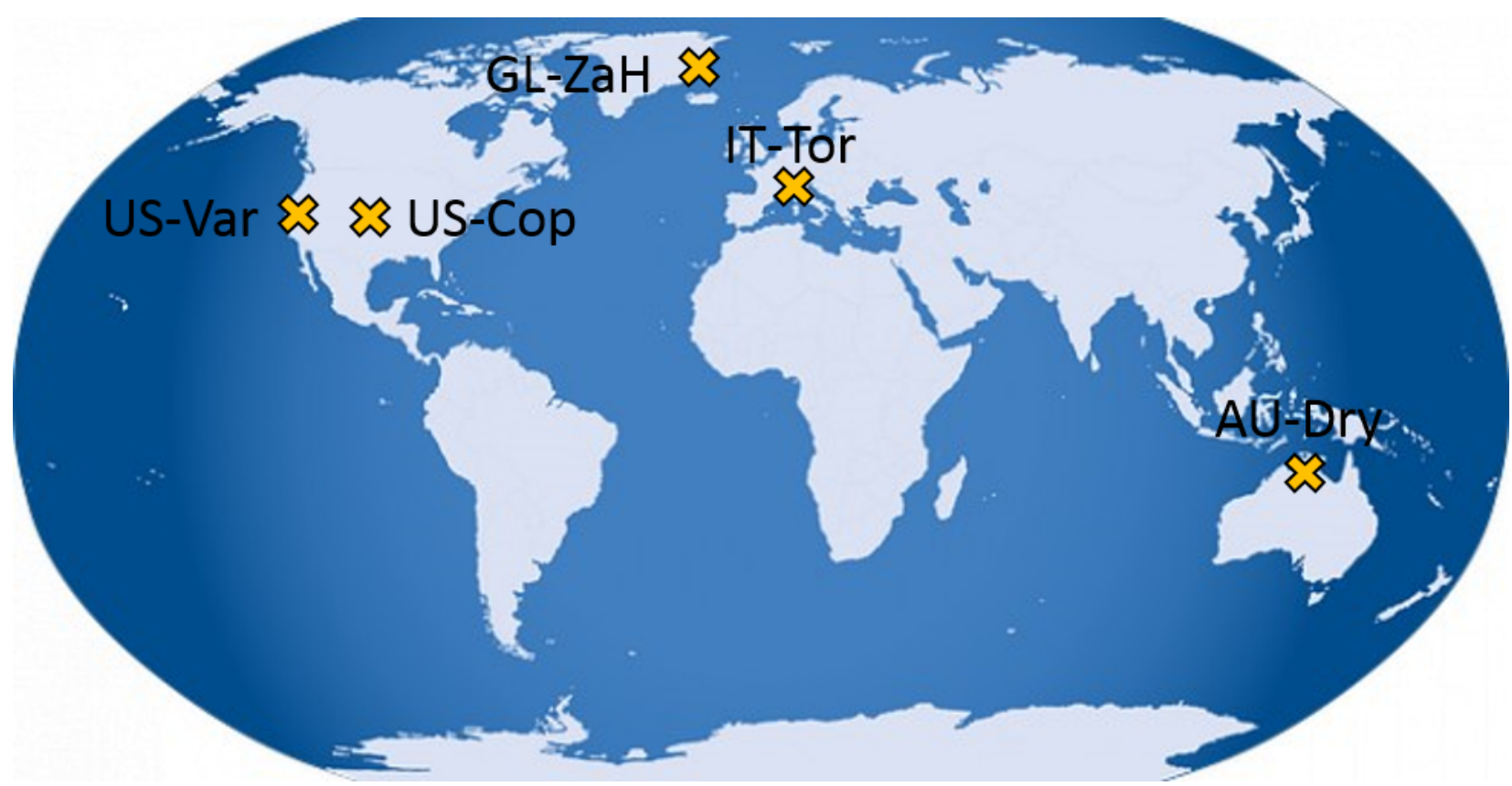

Figure 1. Location of the five eddy covariance stations.

The sites differ in terms of climatic conditions: they are located in (i) A (tropical), (ii) B (arid), (iii) C (temperate), (iv) D (continental), and (v) E (polar) climates according to the Koppen classification [38]. In terms of land cover, grassland is the dominant vegetation in each site and was selected as the reference ecosystem, since it is one of the most widespread 
among all the major biomes on Earth. In addition, it occurs under a wide range of climatic conditions [36]. As regards the climatic conditions, each of the five main groups selected for the present study is defined by temperature criteria, except for the B climate, which has a low amount of annual rainfall. Group $\mathrm{A}$ is characterized by the temperature of the coolest month, higher than or equal to $18^{\circ} \mathrm{C}$. Type $\mathrm{C}$ has the temperature of the coldest month, ranging between $-3{ }^{\circ} \mathrm{C}$ and $18^{\circ} \mathrm{C}$, and the temperature of the warmest month, above $10^{\circ} \mathrm{C}$. Group D has the coldest month, with a temperature lower than $-3{ }^{\circ} \mathrm{C}$, while the hottest month featured an average temperature higher than $10^{\circ} \mathrm{C}$. Climate $\mathrm{E}$ has at least one month of the year with temperatures lower than $10^{\circ} \mathrm{C}$. The input datasets, required by the selected ET models, include measurements of precipitation, wind speed, relative air humidity, air temperature and solar radiation, at a sub-hourly time-step. The Dry River station (AUDry) [39-41] is characterized by Tropical savanna climate (identified by the symbol Aw according to Koppen classification). The flux tower of the site consists of a LI-7500A (LICOR, Lincoln, NE, USA) infrared gas analyser and a CSAT3 sonic anemometer (Campbell Scientific, Logan, UT, USA). In addition, a CS702 tipping bucket rain gauge (Campbell Scientific, Logan, UT, USA), TCAV soil thermocouple probes, CN3 heat flux plates and a CNR1- net radiometer complete the equipment. The Corral Pocket site (US-Cop) [42-44] has a cold, semi-arid climate (BSk). The equipment of the study site consists of an eddy covariance (EC) station, a meteorological station and soil moisture and soil temperature sensors. The Eddy covariance station called Vaira Ranch "US-Var" [45,46] is located in an area with a hot-summer Mediterranean climate (Csa). The site includes a 2-meter-high eddy covariance tower with a triaxial sonic anemometer (Model 1352, Gill Instruments Ltd., Lymington, UK) and a $\mathrm{CO}_{2}$ and water infrared gas analyser (IRGA, Li 7500, Li-Cor Inc., Lincoln, NE, USA). In addition, the site is equipped with a net radiometer, a pyranometer, a shielded and aspirated sensor and a reflectometry sensor. The experimental site of Torgnon (IT-Tor) $[47,48]$ is characterized by a subarctic climate. The EC station is equipped with a CSAT3 three-dimensional sonic anemometer and a LI-7500 open-path infrared gas analyser. The Eddy covariance station called Zackenberg Heath (GL-ZaH) $[49,50]$ is located in an area with Tundra climate. The flux measurements have been provided by an EC system consisting of an infrared gas analyzer LI-7000 (LI-COR, Lincoln, NE, USA) and a 3D sonic anemometer Gill R3 (Gill Instrument Ltd, Lymington; Hampshire, UK ). In addition, a meteorological station allows for additional weather measurements. The five aforementioned sites have been selected among a wide range of EC experimental locations belonging to the Fluxnet platform with the required climate and vegetation types, since they offer the longest flux time series and more complete datasets, including all the variables required in the present study, with few or no periods of gaps or missing data. The sites climatic characterizations, with the monthly patterns of precipitation and air temperature can be found in Figure 2. The rainfall and temperature data used for the climate characterization of the sites have been provided by climate-data.org, whose archives are based on European Centre for Medium-Range Weather Forecasts (ECMWF) data. The model uses more than 1.8 billion datapoints and and has a resolution of $0.1-0.25$ grade. The rainfall/temperature data span moves from 1999 and 2019. The moisture index $\left(I_{D M}\right)$ proposed by de Martonne [51] has been calculated for each investigated site so as to provide a more detailed climatic characterization. It can be estimated as

$$
I_{D M}=\frac{P}{T+10}
$$

where $P$ is the annual mean precipitation in $\mathrm{mm}$ and $T$ is the annual mean air temperature in ${ }^{\circ} \mathrm{C}$. The moisture index is related to the climatic regime, indeed, Arid, Semi-Arid, Mediterranean, Semi-Humid, Humid, Very Humid, Extremely Humid regions are respectively defined by the ranges of $I_{D M}<10 ; 10 \leq I_{D M}<20 ; 20 \leq I_{D M}<24 ; 24 \leq I_{D M}<28$; $28 \leq I_{D M}<35 ; 35 \leq I_{D M}<55 ; I_{D M}>55$.

The value of the moisture index for the five sites and a summary of their main features is available at Table 1 . 


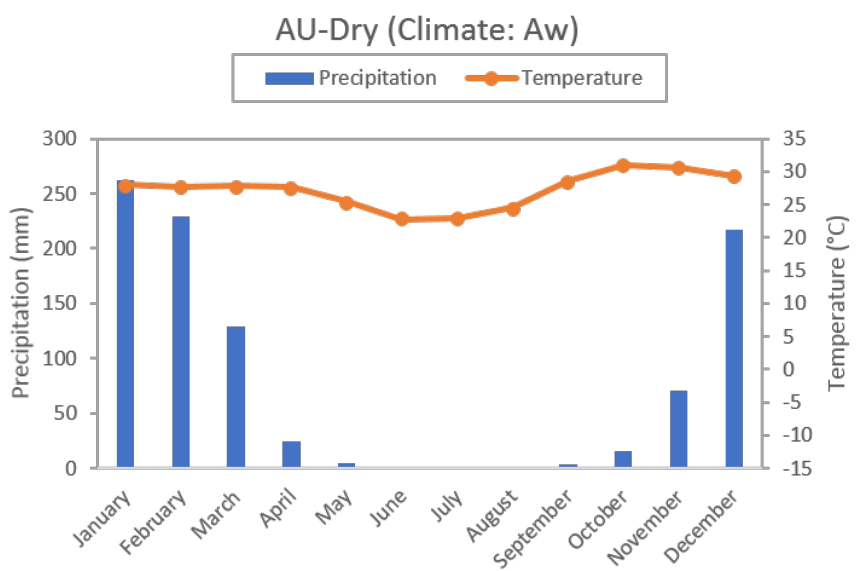

US-Var (Climate: Csa)

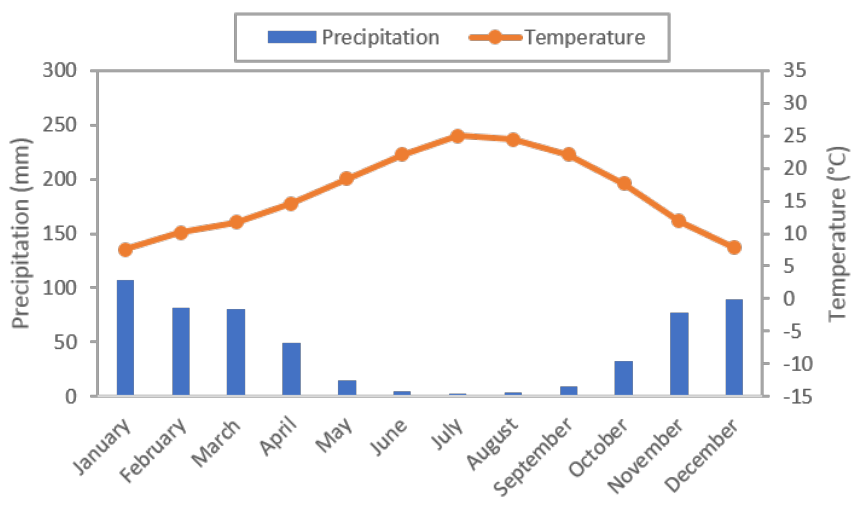

US-Cop (Climate: BSk)

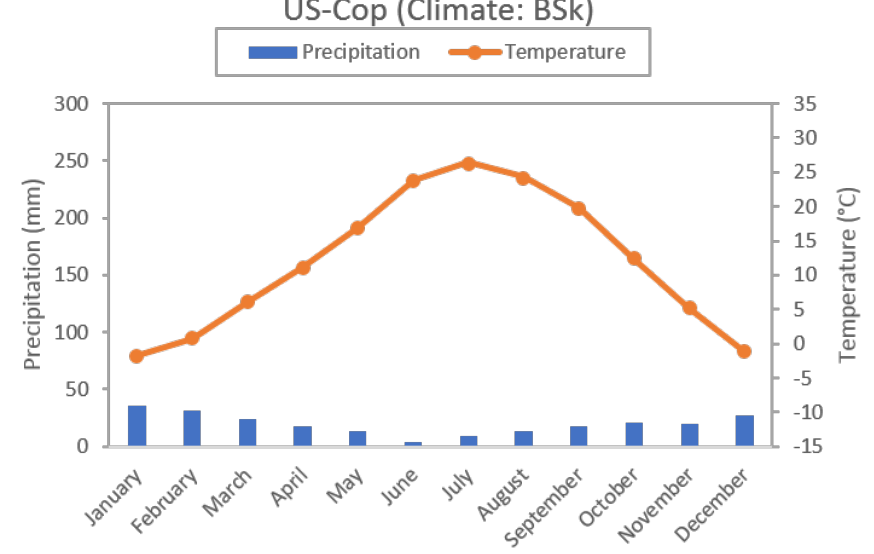

IT-Tor (Climate: Dfc)

Precipitation $\rightarrow$ Temperature

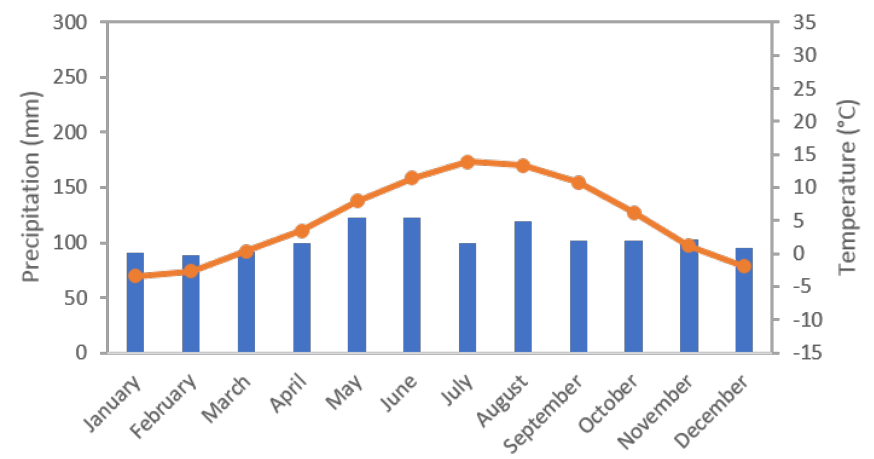

GL-ZaH (Climate: ET)

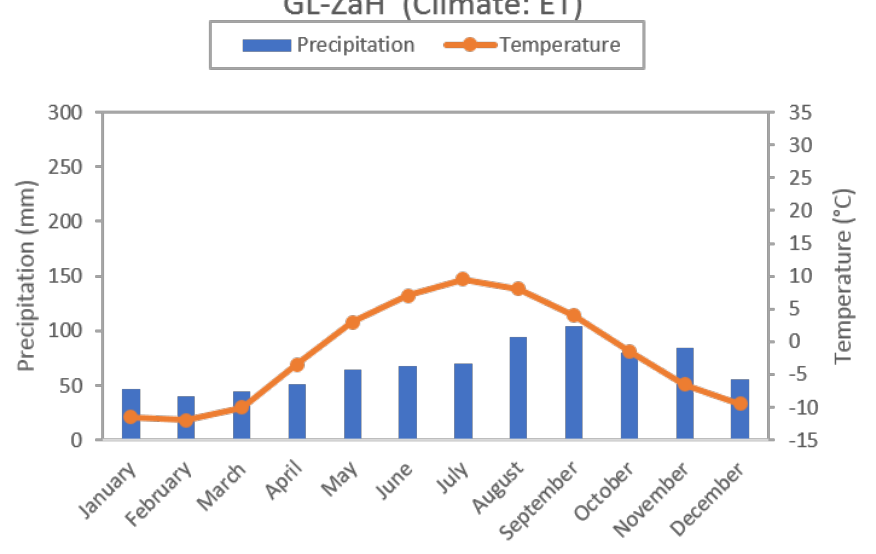

Figure 2. Monthly patterns of precipitation and air temperature for the five considered sites. 


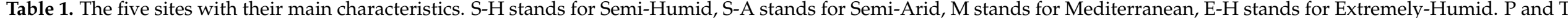
values refer to their annual means.

\begin{tabular}{|c|c|c|c|c|c|c|c|c|c|c|}
\hline Site ID & Site Name & Latitude & Longitude & Climate & $I_{D M}$ (Regime) & Elevation (m) & $\mathbf{P}(\mathrm{mm})$ & $\mathrm{T}\left({ }^{\circ} \mathrm{C}\right)$ & $\begin{array}{l}\text { Prevailing Grassland } \\
\text { Species }\end{array}$ & FLUXNET DOI: \\
\hline AU-Dry & Dry River & -15.2588 & 132.3706 & $A w$ & $25.7(\mathrm{~S}-\mathrm{H})$ & 180 & 956 & 27.22 & \multirow{2}{*}{$\begin{array}{c}\text { Eucalyptus and latifolia } \\
\text { Hilaria jamesii and Stipa } \\
\text { hymenoides }\end{array}$} & 10.18140/FLX/1440197 \\
\hline US-Cop & Corral Pocket & 38.09 & -109.39 & BSk & $10.6(\mathrm{~S}-\mathrm{A})$ & 1520 & 234 & 11.98 & & 10.18140/FLX/1440100 \\
\hline US-Var & Vaira Ranch & 38.41329 & -120.951 & Csa & $21.0(\mathrm{M})$ & 129 & 550 & 16.10 & $\begin{array}{l}\text { Purple false brome and } \\
\text { smooth cat's ear }\end{array}$ & 10.18140/FLX/1440094 \\
\hline IT-Tor & Torgnon & 45.84444 & 7.57806 & Dfc & $82.2(\mathrm{E}-\mathrm{H})$ & 2160 & 1237 & 5.04 & $\begin{array}{l}\text { Nardus stricta L.and } \\
\text { Festuca nigrescens All. }\end{array}$ & 10.18140/FLX/1440237 \\
\hline GL-ZaH & Zackenberg Heath & 74.47328 & -20.5503 & ET & $99.0(\mathrm{E}-\mathrm{H})$ & 38 & 801 & -1.91 & $\begin{array}{l}\text { Cassiope tetragona and } \\
\text { Dryas integrifolia }\end{array}$ & 10.18140/FLX/1440224 \\
\hline
\end{tabular}




\subsection{GEOframe Modelling System}

GEOframe-Prospero was implemented as a Java component within GEOframe, an opensource, semi-distributed, component-based hydrological modeling system. It is developed in Java and based on the environmental modeling framework Object Modeling System V3 (OMS3) [31]. Within GEOframe, each part of the hydrological cycle is implemented in a self-contained building block, commonly called component [52]. Components can be joined together to obtain multiple modeling solutions that can accomplish from simple to very complicated tasks. Thanks to its solid informatic infrastructure, GEOframe proved a great flexibility and a great robustness in several applications (e.g., [35,53,54]). More than 50 components are available, which can be grouped in the following categories:

- Geomorphic and DEM analyses;

- Spatial extrapolation/interpolation of meteorological variables;

- Estimation of the radiation budget;

- Estimation of ET;

- Estimation of runoff production;

- Simulation of infiltration;

- Channel routing;

- Travel time analysis;

- Calibration algorithms.

Using the components for geomorphic and DEM analyses [55], the basin can be discretized into Hydrological Response Units (HRUs), i.e., hydrologically similar parts, such as a catchment or a hillslope or one of its parts. The meteorological forcing data can be spatially interpolated using a geostatistical approach, such as the Kriging technique [56]. Both shortwave and longwave radiation components are available for the estimation of the radiation budget $[57,58]$. ET can be estimated using three different formulations: the FAO ET model [32], the Priestley-Taylor model [4], and the Prospero model, tthe object of the present work. Snow melting and the snow water equivalent can also be simulated by three models, as described in [59]. Runoff production is performed by using the Embedded Reservoir Model (ERM) or a combination of its reservoirs [35]. The discharge generated at each hillslope is routed to the outlet using the Muskingum-Cunge method [35]. Travel time analysis of a generic pollutant within the catchment can be done using the approach proposed in $[60,61]$. Moreover, the GEOframe provides an integration of Richards 1D with and without temperature, decoupled and coupled with the Energy budget and integration of Richards Equation (2)D [62]. Model parameters can be calibrated using two algorithms and several objective functions: Let Us CAlibrate (LUCA) [63] and Particle Swarm Optimization (PSO) [64]. A graph-based structure, called NET3 [65], is employed for the management of process simulations. NET3 is designed using a river network/graph structure analogy, where each HRU is a node of the graph, and the channel links are the connections between the nodes. In any NET3 node, a different modeling solution can be implemented and nodes (HRUs or channels) can be connected or disconnected at run-time, through scripting. GEOframe is open source and helps the reproducibility and replicability of research [66]. Developers and users can easily collaborate, share documentation, and archive examples and data within the GEOframe community. All the links for the reproducibility of this work results are detailed in Appendix A. In this context, the modularity of the GEOframe modelling system offers the possibility to have multiple modelling solution for a better estimation of the ET fluxes.

\subsection{The Prospero Model}

The Prospero model (PS) was created e to be the core of a physically based, but computationally efficient, ecohydrological model. It is currently mainly thought to estimate ET, but it could be easily extended to the computation of photosynthesis or as the core of a lysimeter model, able to compute the water and energy exchanges between soil and atmosphere. The basic idea is that the ET is given by the sum of two different processes (Figure 3): E from soils and T from the canopy, both from the fraction exposed to direct 
sunlight and from the one in shadow. E from soils is computed according to the FAO Penman-Monteith model, while the $\mathrm{T}$ is computed according to a modified version of the Schymanski and Or [33] model, which was upscaled in order to face the T at canopy level and the mass conservation when there is water stress.



Figure 3. Conceptual scheme of the GEOframe-Prospero model.

The deployment of the T component within the Prospero model started from the well-known energy balance equation:

$$
R_{s}=R_{l l}+E+H+G
$$

and

$$
R_{l l}=R_{l}^{\uparrow}-R_{l}^{\downarrow}
$$

where:

- $\quad \mathrm{R}_{s}$ is the net shortwave radiation $\left[\mathrm{W} \mathrm{m}^{-2}\right]$

- $\quad$ E is ET $\left[\mathrm{W} \mathrm{m}^{-2}\right]$

- $\quad \mathrm{H}$ is the thermal energy transport $\left[\mathrm{W} \mathrm{m}^{-2}\right]$

- $\mathrm{G}$ is the ground heat flux $\left[\mathrm{W} \mathrm{m}^{-2}\right]$

- $\quad \mathrm{R}_{l}^{\uparrow}$ is the upwelling longwave radiation $\left[\mathrm{W} \mathrm{m}^{-2}\right.$ ]

- $\quad \mathrm{R}_{l}^{\downarrow}$ is the downwelling longwave radiation [W $\mathrm{m}^{-2}$ ]

The Prospero ET model is based on the the SO approach [33], but it has been further expanded to work at canopy level and to deal with plant's water stress:

- Modifying the SO model to use the leaf area index to obtain the transpiring surface $\left(\mathrm{A}_{t r}\right)$;

- Considering the stomata opening based on radiation stress [67];

- Adding a stress function, based on the soil moisture, in order to ensure the water balance conservation [32].

To extend this equation to the canopy, we decided to adopt a two big leaf approach [68-71], using the Sun/Shade model of [72], which allows for the computation of the fraction of canopy in sunlight and in shade and also the radiation absorbed by multiple canopy layers. In particular, Prospero adopts this two leaf, sun-shade approach, while soil is 
treated separately as a further layer. Moreover, air temperature, relative humidity, wind and longwave radiation were considered constant inside the canopy, allowing to consider it as a single big leaf that emits latent heat proportionally to the corresponding area and to the shortwave radiation. The sun-shade approach can be considered valid for any type of investigated canopy (from grasslands to forests).

The SO [33] approach overcomes some limitations of the Penman-Monteith equation, such as a wrong representation of transpiring area and of the leaf thermal capacity and its feedback on energy balance. In fact, an incorrect representation of the transpiring area of a leaf could impact on the whole energy balance. Therefore, the energy budget in Equation (2) can be rewritten in function of the area able to exchange fluxes and of the equilibrium leaf temperature, as:

$$
R_{s}=a_{s H} \cdot A_{t r} \cdot R_{l l}\left(T_{l}\right)+a_{s E} \cdot A_{t r} \cdot E_{l}\left(T_{l}\right)+a_{s H} \cdot A_{t r} \cdot H_{l}\left(T_{l}\right)
$$

where:

- $a_{S H}$ is the side of the surface exchanging sensible heat (1 for soil, 2 for leaves) [-],

- $a_{S E}$ is the side of the surface exchanging latent heat (1 for amphistomatous leaves) [-],

- $A_{t r}$ is the area exchanging fluxes (radiation, sensible and latent heat) $\left[\mathrm{m}^{2} \mathrm{~m}^{-2}\right]$,

- $T_{l}$ is the equilibrium leaf temperature $[\mathrm{K}]$.

where the longwave in computed as

$$
R_{l l}=a_{s H} \cdot A_{t r} \cdot \epsilon_{l} \sigma\left(T_{l}^{4}-T_{a}^{4}\right)
$$

the $T$ is computed as

$$
E_{l}=c_{E}\left(a_{s E}, A_{t r}\right) \cdot\left[\Delta_{e}\left(T_{l}-T_{a}\right)+P_{w s}-P_{w}\right]
$$

the sensible heat is computed as

$$
H_{l}=c_{H}\left(a_{s H}, A_{t r}\right) \cdot\left[\left(T_{l}-T_{a}\right)\right]
$$

$A_{t r}$ is the transpiring surface for unit of ground surface [-], $a_{S E}$ are the sides of surface exchanging latent heat, equal to 1 for hypostomatous, 2 for amphistomatous [-]; $a_{S H}$ are the sides of surface exchanging sensible heat and longwave radiation, equal to 1 for soil, 2 for leaves [-]; $P_{w s}$ and $P_{w}$ are the saturation water vapour pressure and the water vapour pressure.

Eventually, the leaf temperature (for each layer treated) $T_{l}$ is computed as

$$
T_{l}=\frac{R s+a_{s H} \cdot A_{t r} \cdot \epsilon_{l} \sigma 4 T_{a}^{4}+c_{H}\left(a_{s H}, A_{t r}\right) \cdot T_{a}+c_{E}\left(a_{s E}, A_{t r}, g_{s}\right) \cdot\left(\Delta_{e} T a+P_{w}-P_{w s}\right)}{c_{H}\left(a_{s H}, A_{t r}\right)+c_{E}\left(a_{s E}, A_{t r}, g s\right) \Delta_{e}+a_{s H} \cdot A_{t r} \epsilon_{l} \sigma T_{a}^{3}}
$$

where $g_{s}$ is the stomatal conductance $\left[\mathrm{m} \mathrm{s}^{-1}\right]$. The authors decided to include a modified version of the stomatal conductance proposed in Schymanski and Or [33], based on [73], according to which

$$
g_{s}=g_{s, \max } \cdot f\left(R_{P A R}\right) \cdot f\left(T_{a}\right) \cdot f(V P D) \cdot f(\theta)
$$

where $f\left(R_{P A R}\right)$ is the stress factor due to the fraction of absorbed photosynthetically-active radiation, $f\left(T_{a}\right)$ is the stress factor due to the air temperature, $f(V P D)$ is the stress factor due to the vapour pressure deficit and $f(\theta)$ is the stress factor due the soil water content.

A detailed description of the stress function in the Appendix C. Further information on the complete deployment of Prospero model can be found at Bottazzi [74].

\subsection{Classical ET Model Descriptions}

In addition to the Prospero model, two classical ET models were implemented as components in GEOframe and compared to the results provided by Prospero for each of 
the previously described sites. These models were selected, among many others belonging to the same classes, since they were widely used in previous studies and returned very acceptable and accurate results $[75,76]$. In addition, they require a small number of meteorological variables as input parameters, which are easily available from local weather stations. In particular, these models belong to different categories: the Priestley-Taylor (PT) model is a radiation-based method, where the principal weather parameter affecting ET is the radiation, while the FAO Penman-Monteith (FAO) model is a combination-type approach, where ET is affected by the combination of temperature, radiation and atmospheric drivers, including air humidity and wind speed. A brief description of the methods can be found below. Priestley-Taylor (PT) model can be expressed as

$$
E T_{P T}=\frac{1}{\lambda} \alpha_{P T}\left[\frac{\Delta}{\Delta+\gamma}\left(R_{n}-G_{\text {soil }}\right)\right]
$$

where $\alpha_{P T}$ represents the advection correction coefficient set at the value of 1.26 and is dimensionless, $\lambda$ represents the latent heat of vaporization $\left(\mathrm{MJ} \mathrm{kg}^{-1}\right)$, it has been set at 2.45 , as it varies only slightly over normal temperature ranges. $R_{n}$ represents the net radiation $\left(\mathrm{MJ} \mathrm{m}^{-2} \mathrm{~d}^{-1}\right), G_{\text {soil }}$ represents the soil heat-flux density at the soil surface $\left(\mathrm{MJ} \mathrm{m}^{-2} \mathrm{~d}^{-1}\right), \Delta$ is the slope of the saturation vapor pressure-temperature curve $\left(\mathrm{kPa}^{\circ} \mathrm{C}^{-1}\right)$ expressed as

$$
\Delta=\frac{4098\left[0.610 \exp \left(\frac{17.27 T_{\text {mean }}}{T_{\text {mean }}+237.3}\right)\right]}{\left(237.3+T_{\text {mean }}\right)^{2}}
$$

$T_{\text {mean }}$ is the average daily temperature $\left({ }^{\circ} \mathrm{C}\right)$. The variable $\gamma$ represents the psychrometric constant $\left(\mathrm{kPa}^{\circ} \mathrm{C}^{-1}\right)$.

The FAO-Penman-Monteith (FAO) equation can be written in the form

$$
E T_{P M}=\frac{1}{\lambda}\left[\frac{\Delta}{\Delta+\gamma}\left(R_{n}-G_{\text {soil }}\right)\right]+\left[\frac{\gamma}{\Delta+\gamma} E_{A}\right]
$$

and $E_{A}$ represents the drying power of the air, which is expressed as

$$
E_{A}=2.6(1+0.54 u)\left(e_{s}-e_{a}\right)
$$

where $u$ represents the wind speed $\left(\mathrm{ms}^{-1}\right), e_{S}$ represents the saturation vapor pressure $(\mathrm{kPa})$, function of the maximum and minimum temperature and the parameter $e_{a}$ represents the vapor pressure $(\mathrm{kPa})$ derived from the maximum and minimum relative humidity.

\subsection{Calibration and Validation}

Two different applications of the chosen three models (PS, FAO and PT) are proposed. In the first, the model parameters were set to te literature values and their results were directly compared against ET fluxes derived by EC observations, both at hourly and at daily time-steps. Four indices of goodness-of-fit (GOF) were computed to measure the agreement between the simulated and measured data: Root Mean Square Error (RMSE), Mean Absolute Error (MAE), coefficient of determination $R^{2}$ and the index of agreement (D). Further details about the GOFs are reported in Appendix B. This first application was primarily made since the authors want to demonstrate the goodness of the models when their parameters cannot be calibrated against measured data.

In the second application, the model parameters were first calibrated, at hourly timesteps, against a subset of measured data, using LUCA calibration within GEOframe and than validated against a different subset of measured data. Eventually, the performances of the models after calibration were also assessed at daily time-steps, keeping the same calibrated values. This second application is also interesting, since it shows the integration 
of the three models within the GEOframe framework, which allows for effortless parameter calibrations, when data are available.

The parameters to be calibrated for the PS model are the vapour pressure deficit $\left(\mathrm{VPD}_{0}\right)$; the lower and higher temperature (respectively, $\left.T_{l}, T_{h}\right)$; the temperature at maximum conductance $\left(T_{0}\right)$; the water content at wilting point $\left(\theta_{W P}\right)$ and the water content at field capacity $\left(\theta_{F C}\right)$, which allow for the calculatation of the stress coefficient used when moderate or intense water stress is imposed with the aim of switching from potential to actual ET; the slope $\left(\alpha_{R A D}\right)$ and shape $\left(\theta_{R A D}\right)$ parameters of the stress function $f\left(R_{P A R}\right)$. In particular, $\mathrm{VPD}_{0}$ is defined as the difference between the vapor pressure at the saturation condition and the actual water vapor pressure of the air. The parameters $T_{l}, T_{h}, T_{0}$, respectively, refer to the lower and upper temperature of the range for which a positive stomatal conductance is predicted and the temperature at the maximum stomatal conductance. $\theta_{W P}$ and $\theta_{F C}$ represent the soil moisture corresponding, respectively, to the the minimum amount of water into the ground required to prevent plants withering and to the amount held in the soil after excess water has drained away. The parameters $\alpha_{R A D}$ and $\theta_{R A D}$ allow to quantify the total solar radiation stress. $\theta_{W P}$ and $\theta_{F C}$ are also calibrated in the Penman-Monteith approach, while, for the PT model, $\alpha_{P T}$ is the selected calibration variable. The latter is a coefficient used to take the effect of the drying power of the air on ET into account. All the above-mentioned parameters are crucial to the ET assessment and they impact this process in different ways. With reference to $\mathrm{VPD}_{0}$, when it increases, the atmospheric demand for water and, consequently, the ET fluxes increase too. The lower, higher and optimal temperatures help to define the air temperature stress function, as well as $\left(\alpha_{R A D}\right)$ and $\left(\theta_{R A D}\right)$ do for the solar radiation stress function. Both these stress functions regulate the response of the stoma based on external forcings with associated effects on ET losses. The parameters $\theta_{W P}$ and $\theta_{F C}$ impact on the water stress coefficient, which describes the effect of water stress on the crop: higher values of the stress coefficient determine no soil-water-limiting conditions and higher ET fluxes. Finally, $\alpha_{P T}$ allows to consider the reduction in ET, as the soil water content decreases. Further details about the calibration and validation periods, the calibrated parameters for each investigated site and the proposed model are shown in Table 2.

Table 2. Calibration period, validation period and calibrated parameters for each Site and model. Note that VPD ${ }_{0} T_{l}$, $T_{0}, T_{h}, \theta_{W P}, \theta_{F C}, \alpha_{R A D}, \theta_{R A D}, \alpha_{P T}$, respectively, stand for vapour pressure deficit, lower, optimal and higher temperature, the water content at wilting point, the water content at field capacity, the slope and the shape parameters of the total solar radiation stress function and the PT coefficient.

\begin{tabular}{|c|c|c|c|c|}
\hline Site ID & Flux Data Range & Calibration Period & Validation Period & Calibrated Parameters \\
\hline AU-Dry & 2008-2014 & $\begin{array}{l}\text { 1st January 2012-31st } \\
\text { December 2014 }\end{array}$ & $\begin{array}{l}\text { 1st January 2008-31st } \\
\text { December 2011 }\end{array}$ & PS: $\mathrm{VPD}_{0}, T_{l}, T_{0}, T_{h}, \theta_{W P}, \theta_{F C}, \alpha_{R A D}, \theta_{R A D}$ \\
\hline US-Cop & 2001-2007 & $\begin{array}{l}\text { 1st January 2006-31st } \\
\text { December 2007 }\end{array}$ & $\begin{array}{l}\text { 1st January 2001-31st } \\
\text { December 2005 }\end{array}$ & \\
\hline US-Var & 2000-2014 & $\begin{array}{l}\text { 18th February 2007-31st } \\
\text { December } 2014\end{array}$ & $\begin{array}{l}\text { 4th July 2002-26th } \\
\text { December } 2006\end{array}$ & FAO: $\theta_{W P}, \theta_{F C}$ \\
\hline IT-Tor & 2008-2014 & $\begin{array}{c}\text { 1st January 2011-31st } \\
\text { December 2014 }\end{array}$ & $\begin{array}{l}\text { 1st January 2008-31st } \\
\text { December } 2010\end{array}$ & PT: $\alpha_{P T}$ \\
\hline GL-Zah & 2000-2014 & $\begin{array}{l}\text { 18th December 2000-31st } \\
\text { December } 2004\end{array}$ & $\begin{array}{l}\text { 1st January 2005-31st } \\
\text { December 2004 }\end{array}$ & \\
\hline
\end{tabular}

\section{Results and Discussion}

In this Section, the results of the comparison among the performances of three models before and after the calibration procedures are shown and discussed. The calibrated and uncalibrated parameters, and the range of calibration, for each model are listed in Table 3. It is worth noticing that all the calibrated values differ from the literature ones, stressing the importance of using site-specific parameters, when it is possible to perform calibration versus observed data. What is also evident is that some calibrated values, e.g., the PT $\alpha$, are coinciding with the lower value of the calibration range meaning that the calibration should always be supervised, since the range were chosen to be physically based [32,77-79]. 
In fact, the choice to widen the ranges of calibration would have, probably, led to even better GOFs, but parameters with little meaning, from the process physics perspective.

Table 3. Uncalibrated and calibrated values and range of the parameters of the three considered models, for each site.

\begin{tabular}{|c|c|c|c|c|c|c|c|c|c|c|c|}
\hline & \multicolumn{2}{|c|}{ AU-Dry } & \multicolumn{2}{|c|}{ US-Cop } & \multicolumn{2}{|c|}{ US-Var } & \multicolumn{2}{|c|}{ IT-Tor } & \multicolumn{2}{|c|}{ GL-Zah } & \multirow[b]{2}{*}{ Range } \\
\hline & Param & Cal. & Param & Cal. & Param & Cal. & Param & Cal. & Param & Cal. & \\
\hline \multicolumn{12}{|c|}{ Penman-Monteith FAO } \\
\hline$\theta_{W P}$ & 0.12 & 0.060 & 0.12 & 0.083 & 0.12 & 0.057 & 0.12 & 0.055 & 0.12 & 0.119 & $0.04-0.15$ \\
\hline$\theta_{F C}$ & 0.27 & 0.180 & 0.27 & 0.239 & 0.27 & 0.160 & 0.27 & 0.181 & 0.27 & 0.27 & $0.16-0.40$ \\
\hline \multicolumn{12}{|c|}{ Priestley-Taylor } \\
\hline$\alpha_{P T}$ & 1.26 & 0.70 & 1.26 & 0.70 & 1.26 & 0.70 & 1.26 & 0.96 & 1.26 & 0.70 & $0.7-1.8$ \\
\hline \multicolumn{12}{|c|}{ Prospero } \\
\hline$\theta_{W P}$ & 0.12 & 0.04 & 0.12 & 0.122 & 0.12 & 0.040 & 0.12 & 0.055 & 0.12 & 0.051 & $0.04-0.15$ \\
\hline$\theta_{F C}$ & 0.27 & 0.316 & 0.27 & 0.238 & 0.27 & 0.399 & 0.27 & 0.203 & 0.27 & 0.166 & $0.16-0.40$ \\
\hline $\mathrm{VPD}_{0}$ & 5.0 & 5.61 & 5.0 & 3.07 & 5.0 & 5.0 & 5.0 & 5.0 & 5.0 & 6.90 & $2.0-8.0$ \\
\hline$\alpha_{R A D}$ & 0.005 & 0.007 & 0.005 & 0.006 & 0.005 & 0.005 & 0.005 & 0.003 & 0.005 & 0.005 & $0.003-0.007$ \\
\hline$\theta_{R A D}$ & 0.85 & 0.847 & 0.85 & 0.770 & 0.85 & 0.850 & 0.85 & 0.854 & 0.85 & 0.890 & 0.7-0.9 \\
\hline$T_{l}$ & 0.0 & 4.2 & 0.0 & -2.4 & 0.0 & 0.0 & 0.0 & -2.93 & 0.0 & -4.3 & $-5.0-5.0$ \\
\hline$T_{0}$ & 25.0 & 18.8 & 25.0 & 19.6 & 25.0 & 25.0 & 25.0 & 13.81 & 25.0 & 12.3 & $12.0-25.0$ \\
\hline$T_{h}$ & 50.0 & 31.9 & 50.0 & 40.7 & 50.0 & 50.0 & 50.0 & 33.11 & 50.0 & 41.9 & $25.0-50.0$ \\
\hline
\end{tabular}

This is further confirmed in Table 4 that reports the results, in terms of the four GOFs, for both cases (the calibrated case identifies with a "(C)").

It is immediately clear that the overall performances of both PS model and FAO are really good, with an RMSE and a MAE less than $0.2 \mathrm{~mm} \mathrm{~h}^{-1}$, a $\mathrm{R}^{2}$ and a D generally above the 0.5 , at hourly time-steps. At the same time-step, Priestley-Taylor model shows worse performances, especially in terms of RMSE and MAE, which are often two or three times greater than the other two models. Similar considerations apply to the models performances computed at daily time-steps. Indeed, the daily RMSE and MAE for PT model exceed, respectively, the values of 2 and $1.4 \mathrm{~mm}$ in most cases, while the errors corresponding to PS and FAO approaches, in a few cases, show values higher than $1 \mathrm{~mm}$.

Looking at each sites' results in detail, the best GOFs are obtained for the Italian site Torgnon. For this station, all three models perform equally better, with a slight improvement after the parameter calibration. These results are confirmed if we have a look at Figures 4 and 5, where the annual cumulated, for non-calibrated models, and the time variation of ET, both calibrated and not, are shown, respectively. For this case, for the PS and PT models, the annual cumulated ET is comparable with the measured ET, while it is clear that a mean underestimation of around $200 \mathrm{~mm}$ occurs each year for the FAO model. Figure 5 confirms these results, both for the non-calibrated and calibrated cases. These results, including the strong FAO underestimation, can be explained by looking at Table 5, where the values of soil moisture (minimum, mean, maximum and 25th, 50th and 75th percentiles), for each investigated site, are reported. It is clear that the IT-Tor, together with $\mathrm{GL}-\mathrm{ZaH}$, presents the highest soil moisture values, which, in this case, do not represent a limiting factor for the ET fluxes. 

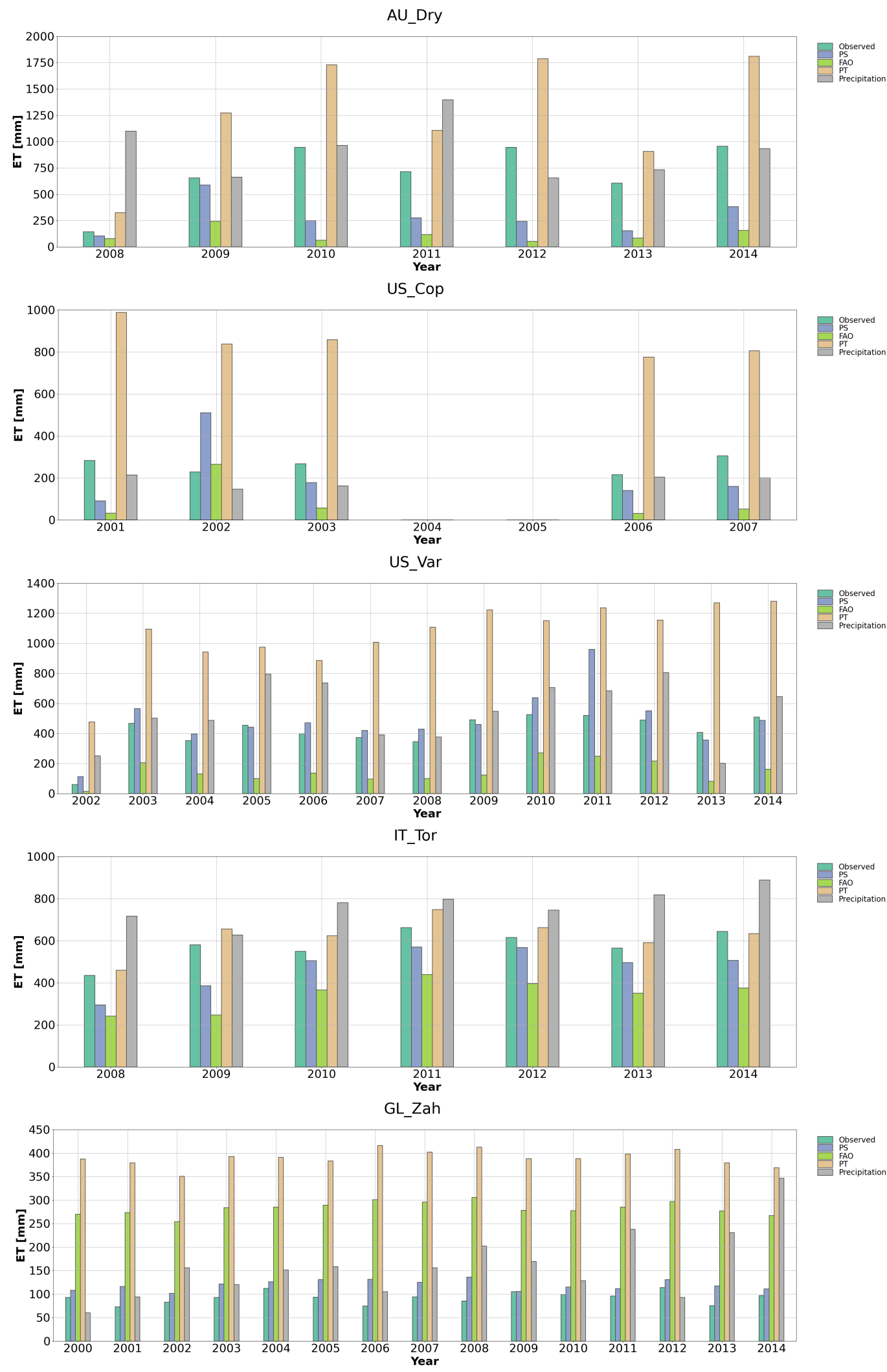

Figure 4. Annual cumulated volumes of ET, modelled (PS, FAO and PT) and measured and annual cumulated precipitation, for each investigated site. 

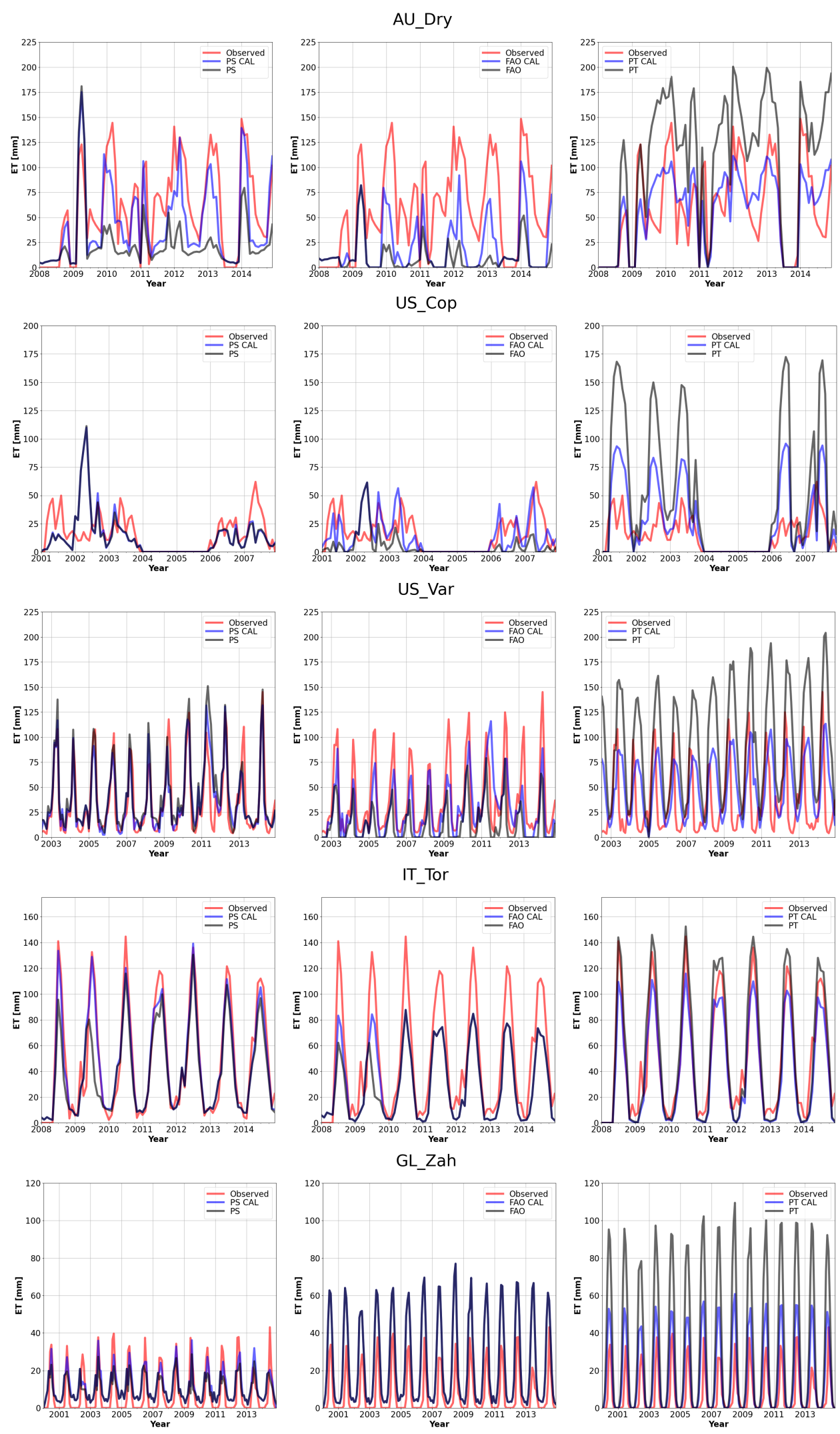

Figure 5. Time variation of the measured (red line) and simulated ET, both using uncalibrated parameter (black line) and calibrated parameters (blu line). 
Table 4. Hourly values of GOFs obtained for each site and for the uncalibrated and calibrated (C) cases.

\begin{tabular}{ccccccccccccc}
\hline Index & \multicolumn{3}{c}{${\text { RMSE }\left[\mathbf{m m ~ h}^{-1}\right]}^{-1}$} & \multicolumn{3}{c}{ MAE $\left[\mathbf{m m ~ h}^{-\mathbf{1}}\right]$} & & $\mathbf{R}^{\mathbf{2}}[-]$ & \multicolumn{1}{c}{ D [-] } \\
\hline Model & PS & FAO & PT & PS & FAO & PT & PS & FAO & PT & PS & FAO & PT \\
\hline AU-Dry & 0.15 & 0.17 & 0.22 & 0.08 & 0.10 & 0.12 & 0.6 & 0.4 & 0.8 & 0.7 & 0.6 & 0.8 \\
AU-Dry (C) & 0.12 & 0.15 & 0.11 & 0.07 & 0.09 & 0.06 & 0.8 & 0.6 & 0.8 & 0.9 & 0.7 & 0.9 \\
\hline US-Cop & 0.07 & 0.06 & 0.20 & 0.03 & 0.03 & 0.10 & 0.3 & 0.2 & 0.6 & 0.5 & 0.5 & 0.4 \\
US-Cop (C) & 0.08 & 0.07 & 0.11 & 0.03 & 0.03 & 0.06 & 0.3 & 0.4 & 0.6 & 0.5 & 0.6 & 0.6 \\
\hline US-Var & 0.08 & 0.10 & 0.25 & 0.04 & 0.05 & 0.15 & 0.8 & 0.7 & 0.5 & 0.9 & 0.7 & 0.6 \\
US-Var (C) & 0.08 & 0.08 & 0.15 & 0.04 & 0.04 & 0.09 & 0.8 & 0.8 & 0.5 & 0.9 & 0.9 & 0.7 \\
\hline IT-Tor & 0.07 & 0.07 & 0.07 & 0.03 & 0.03 & 0.04 & 0.87 & 0.89 & 0.93 & 0.92 & 0.89 & 0.95 \\
IT-Tor (C) & 0.06 & 0.06 & 0.05 & 0.03 & 0.03 & 0.03 & 0.91 & 0.92 & 0.93 & 0.95 & 0.92 & 0.96 \\
\hline GL-ZaH & 0.03 & 0.06 & 0.11 & 0.02 & 0.04 & 0.07 & 0.48 & 0.72 & 0.69 & 0.67 & 0.69 & 0.49 \\
GL-ZaH (C) & 0.03 & 0.06 & 0.05 & 0.02 & 0.04 & 0.03 & 0.52 & 0.70 & 0.67 & 0.71 & 0.66 & 0.69 \\
\hline
\end{tabular}

Table 5. Statistical description of the soil moisture data collected in each sites.

\begin{tabular}{cccccc}
\hline Soil Moisture & AU-Dry & US-Cop & US-Var & IT-Tor & GL-ZaH \\
\hline Min & 0.03 & 0.03 & 0.00 & 0.11 & 0.32 \\
Mean & 0.07 & 0.10 & 0.12 & 0.26 & 0.38 \\
Max & 0.31 & 0.17 & 0.51 & 0.69 & 0.52 \\
$25 \%$ & 0.04 & 0.07 & 0.04 & 0.22 & 0.35 \\
$50 \%$ & 0.04 & 0.11 & 0.09 & 0.26 & 0.36 \\
$75 \%$ & 0.08 & 0.13 & 0.21 & 0.30 & 0.40 \\
\hline
\end{tabular}

The station with the worst indices is the AU-Dry, where the RMSE values are higher than in all the other stations for all the models. This could be for two reasons. First of all, the site has a temperature regime which strongly differs from the others. Indeed, the temperature is lower when no rain occurs, while it reaches its maximum value during the wettest months. In the other sites, temperature and precipitation are in opposite-phase (Figure 2). This may have affected the models' perfomances. The other reason is to be found in the particularly low values of soil moisture, as reported in Table 5 . It can be seen that, most of the time, the soil moisture is lower than the wilting point (Table 5); this has a strong impact on the stress function linked to the water content in the soil. In fact, it can be seen in Figure 4 that, on an annual scale, in the uncalibrated case, the quantities of ET are strongly underestimated. As an exception to this case, generally Prospero has better performances, due to the closure of the energy balance through the equilibrium temperature (Formula (8)), a correct representation of the transpiring surface given by the Sun/Shade canopy model, which can discriminate between the illuminated and shaded breathable surface. This separation allows us to write three different energy balances in Prospero, one for the sunlit surface, one for the shaded one and one for the soil. Moreover, the stress functions, and especially the one based on the soil water content, enhance the performance of Prospero, allowing the conservation of the water mass. This can be seen in the cases of US-Var, IT-Tor and GL-Zah, where the soil moisture values of the site are, on average, quite high (Table 5). In fact, in these cases, Prospero obtains excellent results, even not calibrated, both at hourly and at annual scale, as can be seen in Table 4 and Figure 4. Annual volumes, simulated by the PS model, are always comparable, with small (100 mm/year, generally less than $25 \%$ ) to really negligible differences for all the stations. From a climatic perspective, it can be said that the PS model shows higher performances in the sites with wetter climatic regimes. Indeed, the sites IT-Tor and GL-Zah, which present the lowest errors, are featured by an Extremely Humid regime according to the moisture index (Table 1). Therefore, the prediction accuracy decreases, moving from very wet to arid sites. Looking at both the Figures 4 and 5, for the three stations, US-Cop, Us-Var and GL-Zah, despite the comparable GOFs, PT shows a great overestimation, both in the non-calibrated and calibrated cases. The opposite behaviour is shown for station US-Cop and Us-Var for the FAO model that shows a systematic underestimation of the annual 
volumes, which slightly improves for the calibrated case. For the GL-Zah station, the FAO model overestimates the annual volumes of around $200 \mathrm{~mm}$ each year.

The model which is most impacted by the calibration procedure is PT. Indeed, at hourly time-steps, the errors decrease to more than one half of the initial value. An emblematic case is the site GL-Zah where the RMSE moves from $0.11 \mathrm{~mm} \mathrm{~h}^{-1}$ to $0.05 \mathrm{~mm} \mathrm{~h}^{-1}$ while the MAE decreases from $0.07 \mathrm{~mm} \mathrm{~h}^{-1}$ to $0.03 \mathrm{~mm} \mathrm{~h}^{-1}$ with a reduction close to $60 \%$. On the other hand, the values of $\alpha$ calibrated, for PT, return the same value in all sites and for all climates, i.e., the minimum of the calibration interval.

At the daily time scale (Table 6), the improvement due to the calibration process of PT appears substantial, even if less evident, with the exception of the site US-Cop, where the RMSE decreases by more than $100 \%$ and MAE of about $60 \%$. The effect of the calibration process is lower for the other models where, in terms of RMSE, a reduction of, at most, $20 \%$ is reached, while in terms of MAE, an improvement no higher than $10 \%$ can be observed. Since the prediction accuracy of the PT model is so heavily impacted by the calibration process, in the context of data scarcity, where no or very few flux measurements are available, it results the least recommended for the prediction of the ET. So, in general, when measured values of ET are missing, the used model can be employed as originally proposed in literature, namely without site-specific coefficients with the consequent reduction of the predictive accuracy [75]. When further in-situ measurements are not available such as the net radiation or the soil heat flux, they can be derived using empirical formulations [32] which only require readily available temperature time series as input data. Moreover, for the calculation of $R n$, there are several model components available in the GEOframe system [57]. Eventually, a wide literature available becomes available to derive soil hydraulic parameters from basic soil textural properties [80].

Table 6. Daily values of GOFs obtained for each site and for the uncalibrated and calibrated (C) cases.

\begin{tabular}{ccccccccccccc}
\hline Index & \multicolumn{3}{c}{ RMSE $[\mathrm{mm}]$} & \multicolumn{3}{c}{ MAE $[\mathrm{mm}]$} & & $\mathbf{R}^{2}[-]$ & & & D [-] \\
\hline Model & PS & FAO & PT & PS & FAO & PT & PS & FAO & PT & PS & FAO & PT \\
\hline AU-Dry & 1.9 & 2.2 & 2.3 & 1.4 & 1.8 & 1.8 & 0.51 & 0.36 & 0.74 & 0.65 & 0.51 & 0.73 \\
AU-Dry (C) & 2.1 & 2.3 & 2.1 & 1.4 & 1.7 & 1.4 & 0.40 & 0.34 & 0.28 & 0.62 & 0.54 & 0.58 \\
\hline US-Cop & 0.85 & 0.82 & 2.19 & 0.49 & 0.58 & 1.4 & 0.18 & -0.02 & 0.50 & 0.40 & 0.34 & 0.39 \\
US-Cop (C) & 0.93 & 0.82 & 0.99 & 0.57 & 0.59 & 0.63 & 0.09 & 0.17 & 0.35 & 0.36 & 0.47 & 0.56 \\
\hline US-Var & 0.98 & 1.28 & 2.57 & 0.63 & 0.80 & 1.83 & 0.73 & 0.60 & 0.22 & 0.85 & 0.65 & 0.47 \\
US-Var (C) & 1.22 & 1.26 & 1.57 & 0.78 & 0.80 & 1.15 & 0.55 & 0.52 & 0.19 & 0.74 & 0.68 & 0.54 \\
\hline IT-Tor & 0.86 & 1.07 & 0.79 & 0.57 & 0.71 & 0.52 & 0.86 & 0.88 & 0.92 & 0.91 & 0.84 & 0.95 \\
IT-Tor (C) & 1.51 & 1.59 & 1.52 & 0.86 & 0.97 & 0.86 & 0.60 & 0.62 & 0.62 & 0.76 & 0.70 & 0.76 \\
\hline GL-ZaH & 0.41 & 0.78 & 1.30 & 0.29 & 0.53 & 0.82 & 0.49 & 0.76 & 0.74 & 0.66 & 0.68 & 0.54 \\
GL-ZaH (C) & 0.45 & 0.73 & 0.59 & 0.27 & 0.44 & 0.3 & 0.39 & 0.53 & 0.53 & 0.63 & 0.63 & 0.68 \\
\hline
\end{tabular}

\section{Conclusions}

ET is one of the main components of the water cycle and it plays a key part in water resources' assessment. In light of this, an accurate prediction of this variable is essential, making the need for more and more accurate models an increasingly discussed issue. Within this framework, a new ET model, named Prospero (PS), has been introduced in the component-based hydrological modelling framework, GEOframe. Prospero extends the recently developed S0 model [33] at the canopy level, which overcomes some limitations of the PM model with respect to the representation of the leaf transpiring surfaces. The performances of this model have been compared with those of two of the most commonly used approaches in the scientific literature, which are Priestley-Taylor and Penman-Monteith FAO methods. The comparison has been performed in terms of RMSE, MAE, $\mathrm{R}^{2}$ and D, using a high-quality dataset of selected EC towers at hourly and daily temporal resolutions. The selected stations are AU-Dry, US-Cop, US-Var, IT-Tor, GL-ZaH which are located in different climates but have the same vegetation cover, represented by grassland. Addi- 
tionally, the three method parameters were calibrated to the local conditions using LUCA calibration within GEOframe, in an attempt to reduce the prediction errors.

PS proved to be a robust model since it gave very good results for all the investigate sites, under different climatic conditions. In fact, the results show that, overall, PS returns higher performances than PT and PM, especially in the case of non-calibrated parameters. It follows that, in a context of data scarcity, where, due to the lack of measurements, a calibration procedure cannot be performed, the use of PS is recommended for ET assessment. Indeed, at hourly time steps, the RMSE and MAE reach, at most, $0.15 \mathrm{~mm}$ and $0.08 \mathrm{~mm}$, respectively, while they approach the values of $0.17 \mathrm{~mm}$ and 0.10 for FAO and $0.22 \mathrm{~mm}$ and $0.12 \mathrm{~mm}$ for PT. In case of calibration, PS is always the most accurate model, but the gap with the other methods is narrowed. This implies that the PS model, besides having more parameters, is the least affected by the calibration procedure, while, for PT, the calibration process has the greatest impact. Besides this, Prospero returns temperature, the sensible heat fluxes, and the vapor pressure difference between the evaporating surface and the air, which, for the sake of topic and brevity, were not shown in the present work.

Future research directions of the present work are threefold. From one side, the PS model can be compared to meteorological data-based approaches for the prediction of actual ET, such as the Antecedent precipitation index model or the Advection aridity model $[37,76]$, which are more effective at reproducing the ET fluxes than the potential ET models proposed in the present study. On the other side, since the PS model returns an ET overestimation during the energy-limited periods (particularly evident in GL-Zah site), a threshold mechanism could be applied in order to improve the overall prediction. The approach couples a potential ET model and an actual one (in this case PS) according to a threshold value of net radiation [75]. It would also be interesting to test the model in sites with different land uses, such as forest, cropland and wetland. This would allow for the exploration of all aspects, and an exploration of the behavior of PS approach and, consequently, its prediction accuracy.

Author Contributions: Conceptualization, M.B. (Michele Bottazzi), M.B. (Marialaura Bancheri), M.M., G.B. and R.R.; Data curation, M.B. (Michele Bottazzi) and M.M.; Formal analysis, M.B. (Michele Bottazzi), M.B. (Marialaura Bancheri) and M.M.; Investigation, M.B. (Michele Bottazzi) and M.M.; Methodology, M.B. (Michele Bottazzi), M.B. (Marialaura Bancheri), M.M. and R.R.; Software, M.B. (Michele Bottazzi) and R.R.; Supervision, G.B., A.L. and R.R.; Validation, M.B. (Michele Bottazzi) and M.M.; Writing —original draft, M.B. (Michele Bottazzi), M.B. (Marialaura Bancheri) and M.M.; Writing-review and editing, M.B. (Michele Bottazzi), M.B. (Marialaura Bancheri), M.M., G.B., A.L. and R.R. All authors have read and agreed to the published version of the manuscript.

Funding: This research has been partly supported by the project WATZON "WATer mixing in the critical ZONe: observations and predictions under environmental changes"-Call PRIN 2017 by the Italian Ministry for Research and by the project EcoHydro supported by Eurac Research.

Institutional Review Board Statement: Not applicable.

Informed Consent Statement: Not applicable.

Data Availability Statement: The interested researcher can find the entire OMS project, containing input data, output, sim files, jar files, and the Python script used for the plots, at the following link: https:/ / zenodo.org/record/4643532, accessed on 27 April 2021.

Acknowledgments: This work used eddy covariance data acquired and shared by the FLUXNET community, including these networks: AmeriFlux, AfriFlux, AsiaFlux, CarboAfrica, CarboEuropeIP, CarboItaly, Car-boMont, ChinaFlux, Fluxnet-Canada, GreenGrass, ICOS, KoFlux, LBA, NECC, OzFlux-TERN, TCOS-Siberia, and USCCC. The ERA-Interim reanalysis data are provided by ECMWF and pro-cessed by LSCE. The FLUXNET eddy covariance data processing and harmonization was carried out by the European Fluxes Database Cluster, AmeriFlux Management Project, and Fluxdata project of FLUXNET, with the support of CDIAC and ICOS Ecosystem Thematic Center, and the OzFlux, ChinaFlux and AsiaFlux offices. This research was supported in part by the Office of Science (BER), U.S. Department of Energy, Grant No. DE-FG02-03ER63638. This study uses the rainfall and 
temperature data provided by climate-data.org (https://it.climate-data.org/, accessed on 26 April 2021) under the Attribution-NonCommercial 4.0 International license (CC BY-NC 4.0).

Conflicts of Interest: The authors declare no conflict of interest

\section{Appendix A. Code Availability}

For the present work, version v.1.0 is the version of the codes of the GEOframeProspero package that we used, available at the following link: https://github.com/ geoframecomponents/ETP, accessed on 27 April 2021.

\section{Appendix B. Indices of Goodness of Fit}

- Root-Mean-Square Error

The Root-Mean-Square Error (RMSE) is given by

$$
R M S E=\sqrt{\frac{1}{N} \sum_{i=1}^{N}\left(M_{i}-S_{i}\right)^{2}}
$$

where $M$ and $S$ represent the measured and simulated time-series, respectively, and $N$ is the number of components in the series.

- Mean Absolute Error

$$
M A E=\left(\frac{1}{n}\right) \sum_{i=1}^{N}\left|M_{i}-S_{i}\right|
$$

where $M$ and $S$ represent the measured and simulated time-series, respectively, and $N$ is the number of components in the series.

- Coefficient of determination

$$
R^{2}=\frac{\sum_{i=1}^{N}\left(S_{i}-\overline{M_{i}}\right)^{2}}{\sum_{i=1}^{N}\left(M_{i}-\overline{M_{i}}\right)^{2}}
$$

where $M$ and $S$ represent the measured and simulated time-series, respectively, $N$ is the number of components in the series and $\overline{M_{i}}$ is the mean of measured values.

- Index of agreement

$$
D=1-\frac{\sum_{i=1}^{N}\left(M_{i}-S_{i}\right)^{2}}{\sum_{i=1}^{N}\left(\left|S_{i}-\overline{M_{i}}\right|+\left|M_{i}-\overline{M_{i}}\right|\right)^{2}}
$$

\section{Appendix C. Prospero Stress Functions}

We used the model proposed by [73], but instead of using the stress factor given by the leaf water potential, we used the one based on the soil moisture proposed by FAO approach [81]

$$
g_{s}=g_{s, \max } \cdot f\left(R_{P A R}\right) \cdot f\left(T_{a}\right) \cdot f(V P D) \cdot f(\theta)
$$

where $f(\theta)$ is the normalised stress factor depending on available soil water.

$$
\begin{gathered}
f(\theta)=\frac{T A W-D_{r}}{T A W-R A W}=\frac{T A W-D_{r}}{(1-p) T A W} \\
R A W=p \cdot T A W \\
T A W=1000\left(\theta_{F C}-\theta_{W P}\right) \cdot Z_{r} \\
D_{r}=1000\left(\theta_{F C}-\theta\right) \cdot Z_{r}
\end{gathered}
$$

where: 
- $\quad f(\theta)$ is a dimensionless T reduction factor dependent on available soil water [0-1];

- $\quad D_{r}$ root zone depletion [mm];

- TAW total available soil water in the root zone [mm];

- $\quad \mathrm{p}$ fraction of TAW that a crop can extract from the root zone without suffering water stress [-];

- $\quad \theta_{F C}$ the water content at field capacity $\left[\mathrm{m}^{3} \mathrm{~m}^{-3}\right]$;

- $\quad \theta_{W P}$ the water content at wilting point $\left[\mathrm{m}^{3} \mathrm{~m}^{-3}\right]$;

- $\quad \theta$ the measured water content $\left[\mathrm{m}^{3} \mathrm{~m}^{-3}\right]$;

- $\quad \mathrm{Zr}$ the rooting depth $[\mathrm{m}]$.

Air temperature stress The air temperature stress factor can be computed as:

$$
f(T)=b\left(T_{a}-T_{l}\right)\left(T_{h}-T_{a}\right)^{c}
$$

where $b$ and $c$ are defined as:

$$
\begin{gathered}
c=\frac{T_{h}-T_{0}}{T_{0}-T_{l}} \\
b=\frac{1}{\left(T_{0}-T_{l}\right)\left(T_{h}-T_{0}\right)^{c}}
\end{gathered}
$$

where:

- $\quad T_{0}$ is the temperature at maximum conductance $\left[{ }^{\circ} \mathrm{C}\right]$;

- $\quad T_{l}$ and $T_{h}$ the lower and upper temperature of the range for which a positive stomatal conductance is predicted $\left[{ }^{\circ} \mathrm{C}\right]$.

If $T_{l} \leq T_{\text {air }} \leq T_{h}, \mathrm{f}(\mathrm{T})=0$. We assigned the values for $T_{l}, T_{0}$ and $T_{h}$ equal to $0{ }^{\circ} \mathrm{C}$, $25^{\circ} \mathrm{C}$ and $50{ }^{\circ} \mathrm{C}$. These parameters can be set a priori or calibrated.

Total solar radiation stress The solar radiation stress can be computed as:

$$
f\left(R_{S W}\right)=\left[\frac{1}{2 \theta_{R A D}}\left(\alpha_{R A D} R_{S W}+1-\sqrt{\left(\alpha_{R A D} R_{S W}+1\right)^{2}-4 \theta_{R A D} \alpha_{R A D} R_{S W}}\right)\right]^{-1}
$$

where:

- $\quad \alpha_{R A D}$ and $\theta_{R A D}$ are the slope and shape parameters of the stress function $f\left(R_{S W}\right)$ and are set equal to 0.005 and $0.85[-]$.

$R_{S W}$ is the total solar radiation expressed in $\mu \mathrm{mol} \mathrm{m}^{-2} \mathrm{~s}^{-1}$. If we want to express it in $\mathrm{W} \mathrm{m}^{-2}$ we must include a conversion factor equal to $\approx 1 / 4.6$.

Vapour pressure deficit stress The vapor deficit stress factor can be estimated as:

$$
f(V P D)=1.1 \exp [-0.63 \cdot V P D]
$$

\section{References}

1. Bowen, I.S. The ratio of heat losses by conduction and by evaporation from any water surface. Phys. Rev. 1926, 27, 779. [CrossRef]

2. Penman, H.L. Natural evaporation from open water, bare soil and grass. Proc. R. Soc. Lond. Ser. A. Math. Phys. Sci. 1948, 193, 120-145.

3. Monteith, J.L. Evaporation and environment. Symposia of the Society for Experimental Biology; Cambridge University Press (CUP): Cambridge, UK, 1965; Volume 19, pp. 205-234.

4. Priestley, C.H.B.; Taylor, R. On the assessment of surface heat flux and evaporation using large-scale parameters. Mon. Weather Rev. 1972, 100, 81-92. [CrossRef]

5. Morton, F.I. Operational estimates of areal evapotranspiration and their significance to the science and practice of hydrology. J. Hydrol. 1983, 66, 1-76. [CrossRef] 
6. Famiglietti, J.; Wood, E.F. Multiscale modeling of spatially variable water and energy balance processes. Water Resour. Res. 1994, 30, 3061-3078. [CrossRef]

7. Su, Z.; Jacobs, C. ENVISAT: Actual Evaporation; Beleidscommissie Remote Sensing (BCRS): Delft, The Netherlands, 2001.

8. Brutsaert, W. Evaporation into the Atmosphere: Theory, History and Applications; Springer Science \& Business Media: Berlin/Heidelberg, Germany, 2013; Volume 1.

9. Mobilia, M.; Longobardi, A.; Sartor, J.F. Including a-priori assessment of actual evapotranspiration for green roof daily scale hydrological modelling. Water 2017, 9, 72. [CrossRef]

10. Mobilia, M.; Longobardi, A. Model details, parametrization, and accuracy in daily scale green roof hydrological conceptual simulation. Atmosphere 2020, 11, 575. [CrossRef]

11. Kool, D.; Agam, N.; Lazarovitch, N.; Heitman, J.L.; Sauer, T.J.; Ben-gal, A. A review of approaches for evapotranspiration partitioning. Agric. For. Meteorol. 2014, 184, 56-70. [CrossRef]

12. Wang, K.; Dickinson, R.E. A review of global terrestrial evapotranspiration: Observation, modeling, climatology, and climatic variability. Rev. Geophys. 2012, 50. [CrossRef]

13. Mastrotheodoros, T.; Pappas, C.; Molnar, P.; Burlando, P.; Manoli, G.; Parajka, J.; Rigon, R.; Szeles, B.; Bottazzi, M.; Hadjidoukas, P.; et al. More green and less blue water in the Alps during warmer summers. Nat. Clim. Chang. 2020, 10, 155-161. [CrossRef]

14. Mitchell, P.J.; Veneklaas, E.J.; Lambers, H.; Burgess, S.S. Using multiple trait associations to define hydraulic functional types in plant communities of south-western Australia. Oecologia 2008, 158, 385-397. [CrossRef] [PubMed]

15. Brodribb, T.J.; Holbrook, N.M.; Zwieniecki, M.A.; Palma, B. Leaf hydraulic capacity in ferns, conifers and angiosperms: Impacts on photosynthetic maxima. New Phytol. 2005, 165, 839-846. [CrossRef] [PubMed]

16. Fatichi, S.; Pappas, C.; Ivanov, V.Y. Modeling plant-water interactions: An ecohydrological overview from the cell to the global scale. Wiley Interdiscip. Rev. Water 2016, 3, 327-368. [CrossRef]

17. Hölttä, T.; Mencuccini, M.; Nikinmaa, E. Linking phloem function to structure: Analysis with a coupled xylem-phloem transport model. J. Theor. Biol. 2009, 259, 325-337. [CrossRef]

18. Nikinmaa, E.; Sievänen, R.; Hölttä, T. Dynamics of leaf gas exchange, xylem and phloem transport, water potential and carbohydrate concentration in a realistic 3-D model tree crown. Ann. Bot. 2014, 114, 653-666. [CrossRef] [PubMed]

19. Mackay, D.S.; Roberts, D.E.; Ewers, B.E.; Sperry, J.S.; McDowell, N.G.; Pockman, W.T. Interdependence of chronic hydraulic dysfunction and canopy processes can improve integrated models of tree response to drought. Water Resour. Res. 2015, 51, 6156-6176. [CrossRef]

20. Stroock, A.D.; Pagay, V.V.; Zwieniecki, M.A.; Michele Holbrook, N. The physicochemical hydrodynamics of vascular plants. Annu. Rev. Fluid Mech. 2014, 46, 615-642. [CrossRef]

21. Berger, M.; Moreno, J.; Johannessen, J.A.; Levelt, P.F.; Hanssen, R.F. ESA's sentinel missions in support of Earth system science. Remote Sens. Environ. 2012, 120, 84-90. [CrossRef]

22. Carter, C.; Liang, S. Comprehensive evaluation of empirical algorithms for estimating land surface evapotranspiration. Agric. For. Meteorol. 2018, 256-257, 334-345. [CrossRef]

23. Demirel, M.C.; Mai, J.; Mendiguren, G.; Koch, J.; Samaniego, L.; Stisen, S. Combining satellite data and appropriate objective functions for improved spatial pattern performance of a distributed hydrologic model. Hydrol. Earth Syst. Sci. 2018, 22, 1299-1315. [CrossRef]

24. Prentice, I.C.; Liang, X.; Medlyn, B.E.; Wang, Y.P. Reliable, robust and realistic: The three R's of next-generation land-surface modelling. Atmos. Chem. Phys. 2015, 15, 5987-6005. [CrossRef]

25. Bertoldi, G.; Albertson, J.; Kustas, W.; Li, F.; Anderson, M. On the opposing roles of air temperature and wind speed variability in flux estimation from remotely sensed land surface states. Water Resour. Res. 2007, 43. [CrossRef]

26. Siqueira, M.; Katul, G.; Porporato, A. Soil moisture feedbacks on convection triggers: The role of soil-plant hydrodynamics. J. Hydrometeorol. 2009, 10, 96-112. [CrossRef]

27. Manoli, G.; Bonetti, S.; Domec, J.C.; Putti, M.; Katul, G.; Marani, M. Tree root systems competing for soil moisture in a 3D soil-plant model. Adv. Water Resour. 2014, 66, 32-42. [CrossRef]

28. Jung, M.; Reichstein, M.; Ciais, P.; Seneviratne, S.I.; Sheffield, J.; Goulden, M.L.; Bonan, G.; Cescatti, A.; Chen, J.; De Jeu, R.; et al. Recent decline in the global land evapotranspiration trend due to limited moisture supply. Nature 2010, 467, 951-954. [CrossRef] [PubMed]

29. Pappas, C.; Fatichi, S.; Burlando, P. Modeling terrestrial carbon and water dynamics across climatic gradients: Does plant trait diversity matter? New Phytol. 2016, 209, 137-151. [CrossRef]

30. Mammoliti, E.; Fronzi, D.; Mancini, A.; Valigi, D.; Tazioli, A. WaterbalANce, a WebApp for Thornthwaite-Mather Water Balance Computation: Comparison of Applications in Two European Watersheds. Hydrology 2021, 8, 34. [CrossRef]

31. David, O.; Ascough, J.; Lloyd, W.; Green, T.; Rojas, K.; Leavesley, G.; Ahuja, L. A software engineering perspective on environmental modeling framework design: The Object Modeling System. Environ. Model. Softw. 2013, 39, 201-213. [CrossRef]

32. Allen, R.G.; Pereira, L.S.; Raes, D.; Smith, M. Crop evapotranspiration-Guidelines for computing crop water requirements-FAO Irrigation and drainage paper 56. FAO Rome 1998, 300, D05109.

33. Schymanski, S.J.; Or, D. Leaf-scale experiments reveal an important omission in the Penman-Monteith equation. Hydrol. Earth Syst. Sci. 2017, 21, 685-706. [CrossRef] 
34. Formetta, G.; Antonello, A.; Franceschi, S.; David, O.; Rigon, R. Hydrological modelling with components: A GIS-based open-source framework. Environ. Model. Softw. 2014, 55, 190-200. [CrossRef]

35. Bancheri, M.; Rigon, R.; Manfreda, S. The GEOframe-NewAge Modelling System Applied in a Data Scarce Environment. Water 2020, 12, 86. [CrossRef]

36. Woodward, F.I.; Lomas, M.R.; Kelly, C.K. Global climate and the distribution of plant biomes. Philos. Trans. R. Soc. Lond. Ser. B Biol. Sci. 2004, 359, 1465-1476. [CrossRef] [PubMed]

37. Mobilia, M.; Longobardi, A. Prediction of Potential and Actual Evapotranspiration Fluxes Using Six Meteorological Data-Based Approaches for a Range of Climate and Land Cover Types. ISPRS Int. J. Geo-Inf. 2021, 10, 192. [CrossRef]

38. Köppen, W. Die Wärmezonen der Erde, nach der Dauer der heissen, gemässigten und kalten Zeit und nach der Wirkung der Wärme auf die organische Welt betrachtet. Meteorol. Z. 1884, 1, 5-226.

39. Cernusak, L.A.; Hutley, L.B.; Beringer, J.; Holtum, J.A.; Turner, B.L. Photosynthetic physiology of eucalypts along a sub-continental rainfall gradient in northern Australia. Agric. For. Meteorol. 2011, 151, 1462-1470. [CrossRef]

40. Beringer, J.; Hutley, L.B.; McHugh, I.; Arndt, S.K.; Campbell, D.; Cleugh, H.A.; Cleverly, J.; Resco de Dios, V.; Eamus, D.; Evans, B.; et al. An introduction to the Australian and New Zealand flux tower network-OzFlux. Biogeosciences 2016, 13, 5895-5916. [CrossRef]

41. Beringer, J.; Hutley, L. FLUXNET2015 AU-Dry Dry River, Dataset, 2008-2014. Data Retrieved from FLUXNET. 2014. Available online: https:/ / doi.org/10.18140/FLX/1440197 (accessed on 27 April 2021).

42. Belnap, J.; Reynolds, R.L.; Reheis, M.C.; Phillips, S.L.; Urban, F.E.; Goldstein, H.L. Sediment losses and gains across a gradient of livestock grazing and plant invasion in a cool, semi-arid grassland, Colorado Plateau, USA. Aeolian Res. 2009, 1, 27-43. [CrossRef]

43. Kannenberg, S.A.; Bowling, D.R.; Anderegg, W.R. Hot moments in ecosystem fluxes: High GPP anomalies exert outsized influence on the carbon cycle and are differentially driven by moisture availability across biomes. Environ. Res. Lett. 2020, 15, 054004. [CrossRef]

44. Bowling, D. FLUXNET2015 US-Cop Corral Pocket, Dataset, 2001-2017. Data Retrieved from FLUXNET. 2017. Available online: https:/ / doi.org/10.18140/FLX/1440100 (accessed on 27 April 2021).

45. Ryu, Y.; Baldocchi, D.D.; Ma, S.; Hehn, T. Interannual variability of evapotranspiration and energy exchange over an annual grassland in California. J. Geophys. Res. Atmos. 2008, 113. [CrossRef]

46. Ma, S.; Xu, L.; Verfaillie, J.; Baldocchi, D. FLUXNET2015 US-Var Vaira Ranch Ione, Dataset, 2000-2014. Data Retrieved from FLUXNET. 2014. Available online: https:/ / https:/ / doi.org/10.18140/FLX/1440094 (accessed on 27 April 2021).

47. Galvagno, M.; Wohlfahrt, G.; Cremonese, E.; Rossini, M.; Colombo, R.; Filippa, G.; Julitta, T.; Manca, G.; Siniscalco, C.; Di Cella, U.M.; et al. Phenology and carbon dioxide source/sink strength of a subalpine grassland in response to an exceptionally short snow season. Environ. Res. Lett. 2013, 8, 025008. [CrossRef]

48. Cremonese, E.; Galvagno, M.; Morra di Cella, U.; Migliavacca, M. FLUXNET2015 IT-Tor Torgnon, Dataset, 2008-2014. Data Retrieved from FLUXNET. 2014. Available online: https:/ / doi.org/10.18140/FLX/1440237 (accessed on 27 April 2021).

49. Lund, M.; Falk, J.M.; Friborg, T.; Mbufong, H.N.; Sigsgaard, C.; Soegaard, H.; Tamstorf, M.P. Trends in $\mathrm{CO}_{2}$ exchange in a high Arctic tundra heath, 2000-2010. J. Geophys. Res. Biogeosci. 2012, 117. [CrossRef]

50. Lund, M.; Jackowicz-Korczyński, M.; Abermann, J. FLUXNET2015 GL-ZaH Zackenberg Heath, Dataset, 2000-2014. Data Retrieved from FLUXNET. 2014. Available online: https://doi.org/10.18140/FLX/1440224 (accessed on 27 April 2021).

51. Tabari, H.; Talaee, P.H.; Nadoushani, S.M.; Willems, P.; Marchetto, A. A survey of temperature and precipitation based aridity indices in Iran. Quat. Int. 2014, 345, 158-166. [CrossRef]

52. Argent, R.M. An overview of model integration for environmental applications-components, frameworks and semantics. Environ. Model. Softw. 2004, 19, 219-234. [CrossRef]

53. Abera, W.; Formetta, G.; Borga, M.; Rigon, R. Estimating the water budget components and their variability in a pre-alpine basin with JGrass-NewAGE. Adv. Water Resour. 2017, 104, 37-54. [CrossRef]

54. Abera, W.; Formetta, G.; Brocca, L.; Rigon, R. Modeling the water budget of the Upper Blue Nile basin using the JGrass-NewAge model system and satellite data. Hydrol. Earth Syst. Sci. 2017, 21, 3145-3165. [CrossRef]

55. Rigon, R.; Ghesla, E.; Tiso, C.; Cozzini, A. The HORTON Machine: A System for DEM Analysis The Reference Manual; Università degli Studi di Trento: Trento, Italy, 2006.

56. Bancheri, M.; Serafin, F.; Bottazzi, M.; Abera, W.; Formetta, G.; Rigon, R. The design, deployment, and testing of kriging models in GEOframe with SIK-0.9. 8. Geosci. Model Dev. 2018, 11, 2189-2207. [CrossRef]

57. Formetta, G.; Rigon, R.; Chávez, J.; David, O. Modeling shortwave solar radiation using the JGrass-NewAge system. Geosci. Model Dev. 2013, 6, 915-928. [CrossRef]

58. Formetta, G.; Bancheri, M.; David, O.; Rigon, R. Performance of site-specific parameterizations of longwave radiation. Hydrol. Earth Syst. Sci. 2016, 20, 4641-4654. [CrossRef]

59. Formetta, G.; Kampf, S.K.; David, O.; Rigon, R. Snow water equivalent modeling components in NewAge-JGrass. Geosci. Model Dev. 2014, 7, 725-736. [CrossRef]

60. Rigon, R.; Bancheri, M.; Green, T.R. Age-ranked hydrological budgets and a travel time description of catchment hydrology. Hydrol. Earth Syst. Sci. 2016, 20, 4929. [CrossRef]

61. Rigon, R.; Bancheri, M.; Formetta, G.; de Lavenne, A. The geomorphological unit hydrograph from a historical-critical perspective. Earth Surf. Process. Landf. 2016, 41, 27-37. [CrossRef] 
62. Tubini, N.; Rigon, R. Implementing the Water, HEat and Transport model in GEOframe (WHETGEO): Algorithms, informatics, design patterns, open science features and 1D deployment. 2021, in preparation for GMD.

63. Hay, L.E.; Umemoto, M. Multiple-Objective Stepwise Calibration Using Luca; US Geological Survey: Reston, VA, USA, 2007.

64. Kennedy, J.; Eberhart, R. Particle swarm optimization. In Proceedings of the ICNN'95-International Conference on Neural Networks, Perth, WA, Australia, 27 November-1 December 1995; Volume 4, pp. 1942-1948.

65. Serafin, F. Enabling Modeling Framework with Surrogate Modeling Capabilities and Complex Networks. Ph.D. Thesis, University of Trento, Trento, Italy, 2019.

66. Bancheri, M.; Serafin, F.; Formetta, G.; Rigon, R.; David, O. JGrass-NewAge hydrological system: An open-source platform for the replicability of science. In Proceedings of the EGU General Assembly, Wien, Austria, 23-28 April 2017; p. 17109.

67. Noe, S.M.; Giersch, C. A simple dynamic model of photosynthesis in oak leaves: Coupling leaf conductance and photosynthetic carbon fixation by a variable intracellular CO2 pool. Funct. Plant Biol. 2004, 31, 1195-1204. [CrossRef] [PubMed]

68. Dai, Y.; Dickinson, R.E.; Wang, Y.P. A two-big-leaf model for canopy temperature, photosynthesis, and stomatal conductance. J. Clim. 2004, 17, 2281-2299. [CrossRef]

69. Ryu, Y.; Baldocchi, D.D.; Kobayashi, H.; Van Ingen, C.; Li, J.; Black, T.A.; Beringer, J.; Van Gorsel, E.; Knohl, A.; Law, B.E.; et al. Integration of MODIS land and atmosphere products with a coupled-process model to estimate gross primary productivity and evapotranspiration from $1 \mathrm{~km}$ to global scales. Glob. Biogeochem. Cycles 2011, 25. [CrossRef]

70. Wang, Y.P.; Leuning, R. A two-leaf model for canopy conductance, photosynthesis and partitioning of available energy I: Model description and comparison with a multi-layered model. Agric. For. Meteorol. 1998, 91, 89-111. [CrossRef]

71. Luo, X.; Chen, J.M.; Liu, J.; Black, T.A.; Croft, H.; Staebler, R.; He, L.; Arain, M.A.; Chen, B.; Mo, G.; et al. Comparison of big-leaf, two-big-leaf, and two-leaf upscaling schemes for evapotranspiration estimation using coupled carbon-water modeling. J. Geophys. Res. Biogeosci. 2018, 123, 207-225. [CrossRef]

72. De Pury, D.; Farquhar, G. Simple scaling of photosynthesis from leaves to canopies without the errors of big-leaf models. Plant Cell Environ. 1997, 20, 537-557. [CrossRef]

73. Macfarlane, C.; White, D.; Adams, M. The apparent feed-forward response to vapour pressure deficit of stomata in droughted, field-grown Eucalyptus globulus Labill. Plant Cell Environ. 2004, 27, 1268-1280. [CrossRef]

74. Bottazzi, M. Transpiration Theory and the Prospero Component of GEOframe; University of Trento: Trento, Italy, 2020.

75. Mobilia, M.; Schmidt, M.; Longobardi, A. Modelling Actual Evapotranspiration Seasonal Variability by Meteorological Data-Based Models. Hydrology 2020, 7, 50. [CrossRef]

76. Mobilia, M.; Longobardi, A. Evaluation of meteorological data-based models for potential and actual evapotranspiration losses using flux measurements. In Proceedings of the International Conference on Computational Science and Its Applications, Cagliari, Italy, 1-4 July 2020; pp. 3-18.

77. Jarvis, P. The interpretation of the variations in leaf water potential and stomatal conductance found in canopies in the field. Philos. Trans. R. Soc. Lond. B Biol. Sci. 1976, 273, 593-610.

78. Flint, A.L.; Childs, S.W. Use of the Priestley-Taylor evaporation equation for soil water limited conditions in a small forest clearcut. Agric. For. Meteorol. 1991, 56, 247-260. [CrossRef]

79. Cristea, N.C.; Kampf, S.K.; Burges, S.J. Revised coefficients for Priestley-Taylor and Makkink-Hansen equations for estimating daily reference evapotranspiration. J. Hydrol. Eng. 2013, 18, 1289-1300. [CrossRef]

80. Patil, N.G.; Singh, S.K. Pedotransfer Functions for Estimating Soil Hydraulic Properties: A Review. Pedosphere 2016, 26, 417-430. [CrossRef]

81. Allen, R.G. A Penman for all seasons. J. Irrig. Drain. Eng. 1986, 112, 348-368. [CrossRef] 